\title{
Mathematical modelling of the communication channel between the rail circuit and the inputs devices of automatic locomotive signalization
}

\author{
Oksana Hololobova ${ }^{1}$, Serhii Buriak ${ }^{1, *}$, Volodymyr Havryliuk ${ }^{1}$, Ihor Skovron ${ }^{2}$, and Oleksii Nazarov ${ }^{2}$ \\ ${ }^{1}$ Dnipro National University of Railway Transport named after Academician V. Lazaryan, Department «Automatics and \\ Telecommunications», 49010 Dnipro, Lazaryan street 2, Ukraine \\ ${ }^{2}$ Dnipro National University of Railway Transport named after Academican V. Lazaryan, Department «Transport junctions», 49010 \\ Dnipro, Lazaryan street 2, Ukraine
}

\begin{abstract}
In modern practice of operating under traffic safety conditions, the traffic light signal must be transmitted to the locomotive that moves to it, and duplicate in the driver's cab. However, this communication channel is not protected from external interference. In order to prevent the occurrence of code failure, it is necessary to create conditions under which the automatic locomotive signalling system will distinguish between signals with useful information, from signals with false information. The best way to solve this problem at the first stage is to model the devices. Using the simulation tools of graphical environment of simulation modelling Simulink from Matlab software environment, the software model of the communication channel between the railroad and the input devices of automatic locomotive signalling system was constructed. The created mathematical model with the actual parameters allows us to obtain diagnostic signs of a proper condition, on the basis of which the research is aimed at the identification, recognition and definition of various types of malfunctions, failure, damages and defects in the work of the constituent elements of the system and the signal transmission channel of the automatic locomotive signalling system.
\end{abstract}

\section{Introduction}

In modern practice of operating under traffic safety conditions, the traffic light signal must be transmitted to the locomotive that moves to it, and duplicate in the driver's cab. This problem is performed on most main lines by automatic locomotive signalling of a continuous type with numerical coding (ALSN). However, such a communication channel is not protected from external interference $[1,2]$, the most powerful among which are the components of the traction current, electromagnetic fields of power lines, the asymmetry of the rail circles, the zone of joints, and many others [3-6]. Also, the speed of the train, the vibration caused by the movement and the probability of failure of the outdoor units are very influential. The effect of these factors leads to crashes and failures in the system, which significantly affects the safety of trains [7, 8]. Methods of studying the principles of ALSN used in operation are not perfect. In accordance with the procedure of interaction, the locomotive brigade reports about detecting a violation in the ALSN system during traffic to employees of the traffic service, which record the case and transmit information for consideration by employees of the signalling and communication service. Employees of this service inspect the place where the codes failed, and check the voltage in the track circle. According to the operating experience, if along the track or between the rails it is the rail prepared to replace, the most probable reason for the failure of the codes is its residual magnetization, which mostly appears in the process of cargo operations using electric magnets. In most cases, the causes remain unclear. The highest reliability of the recording and analysis of various system failures is the use of a laboratory car and automated processing of the information received, but this method requires additional financial costs for the maintenance of the laboratory car and technical experts, as well as the need for a direct exit to the relevant site, which is not always convenient and an expedient way [9-11]. Taking into account the great importance of ensuring traffic safety, improving the work of ALSN in order to improve the reception of signals and reduce the impact of interferences of any origin remains relevant at present [12].

In order to prevent the occurrence of code crashes, it is necessary to create conditions under which the system will independently distinguish between signals with useful information, from signals with errors. At the first stage, it is necessary to determine the reference signals used by the system for functioning, and the signals with the most common failures in the transmission of information. The best way to solve this problem is to simulate the operation of the devices, since it allows to

\footnotetext{
*Corresponding author: ser.buryak@gmail.com
} 
carry out the necessary number of experiments without leaving the line of rotation of the trains and to investigate the effect of all the constituent elements of the system separately, both in normal operation and under the influence of obstacles. The most convenient way to solve this problem is mathematical modelling. The mathematical model allows us to study the system in detail, since it allows us to analyze the internal processes of the constituent elements and their interaction with each other and with other objects. The advantages of simulation include repeatability, which allows conducting a sufficient number of experiments under the necessary conditions for the operation of the communication channel between the receiving devices and the rail line. Changes in the simulated signal can be investigated depending on the type and intensity of the effect on the object of the study, or on its individual components. Simulation also provides certainty that allows if necessary to take into account or not take into account their random processes. In addition, on the model example, it is possible to further develop and apply various circuitry solutions to reduce the impact of interferences on the functional capabilities of the ALSN system and the introduction of an automated complex to recognize the type of fault [13-15].

Let's conduct research of ALSN work by constructing a mathematical model of the communication channel of its input devices with a rail line.

\section{Structure and system devices}

All devices that are part of the ALSN can be divided into tracks (transmit the code signal) and locomotive (accept the code signal). Each pass-through traffic light (TL) in a relay locker installed with a track coding equipment consisting of a coding scheme (CS), a code track transmitter (CTT), a transmitter relay (kvT) having its own contact in the primary circuit of the code transformer (CT), the secondary winding of which is connected to the track circuit through the choketransformer CT1 [16]. The transmitter converts the signal indications of the traffic light into the corresponding combination of the numerical pulse code, which consists of a certain number of pulses and pauses of different durations (fig. 1) [16].

In the event of a short circuit of the insulating joints, the coded signals from the neighbouring block section get into the track circuit, which threatens the safety of trains. By alternating the transmitters at each signal unit of the route, the necessary shift in the passage of code pulses in adjacent rail circuits and protection from the influence of code signals from adjacent block sections are achieved.

In the composition of locomotive devices ALSN (fig. 2) [16] includes receiving coils (RC), filter (F), locomotive amplifiers (LA) with pulsed relay (P), decoder block (DB), electropneumatic valves of autostop (EPV), locomotive traffic lights (LTL), locomotive speedometer (SM), arm (button) of vigilance (BV), button (BR) for ignition on a locomotive white traffic light instead of red, as well as a tumbler (switch) DZ to change the interval of time periodic vigilance of the machinists [16].

For the unimpeded passage of the traction current, by passing the insulating joints installed chokestransformers (CT). They are used to transmit the track equipment ALSN code signals to the rail circuit, in additional CT preventing the flow of signal current between adjacent block sections [17, 18].

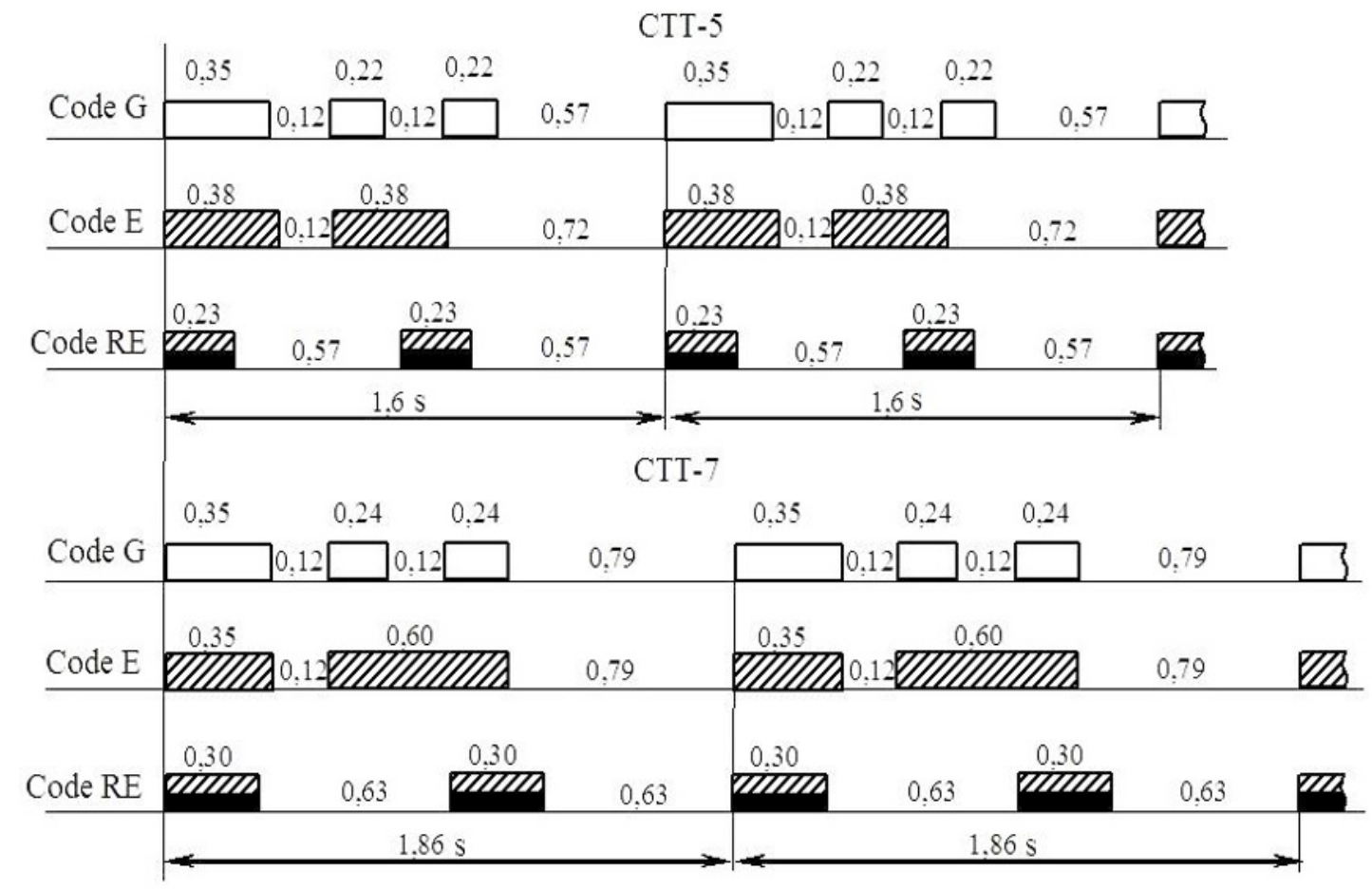

Fig. 1. Time characteristics of numeric codes produced by transmitters of the CCT-5 and CCT-7 types 
The ALSN track devices code current $I_{c}$ on one of the rail threads is directed toward the locomotive, locked through its first wheelset and returns to the power source on the second rail thread (fig. 3) [16]. The leakage of the alternating current pulses in the rails is accompanied by the formation around the rails of the alternating magnetic field $\mathrm{F}_{\mathrm{c}}\left(\mathrm{F}_{\mathrm{cl}}\right.$ - around the left rail, $\mathrm{F}_{\mathrm{cr}}$ - around the right $)$, which permeates the receiving coils and induces an EMF in them $\left(\mathrm{e}_{\mathrm{kl}}-\right.$ in the left coil, the $\mathrm{e}_{\mathrm{kr}}-$ in the right coil), in which moves the locomotive receiving coils that are suspended in front of the first wheel pair on each side [16]. The direction of the code currents $I_{c}$ in each of the rails is opposite (in the left rail the current is directed to "us" and is conventionally indicated by a point, and in the right one - "from us" and is shown by a cross), therefore the induced by these currents EMF $\left(\mathrm{e}_{\mathrm{k}} 1\right.$ and $\mathrm{e}_{\mathrm{kr}}$ ) also have a counter direction. The height of installation of receiving coils over the level of the head of the rail is $150-$ $220 \mathrm{~mm}$. Power lines of the magnetic field, crossing the turns of the RC, give them a alternating EMF, the value of which depends on the value of the code current in the rails and the height of the installation of coils. So, at the height of the location of the $\mathrm{RC}$ above the level of the head of the rail $150 \mathrm{~mm}$ and the code current in the rails $10 \mathrm{~A} 50$ $\mathrm{Hz}$ in the coil, respectively, is given by an EMF, the value of which is approximately $0,65-0,75 \mathrm{~V}$.

To add EMF of both coils they are included sequentially. Two connected successively receiving coils at a frequency of $50 \mathrm{~Hz}$ should have a Q-factor of 3,5-
4,0 and an inductance of 14,0 Gn EMF which is given in open and disconnected from the control panel coils, with a current in the line $10 \mathrm{~A}$ must be $1,3 \mathrm{~V}$. The minimum code current that can be received by the receiving coils for different types of traction and kind of current is from 1,2 A to $2,0 \mathrm{~A}$ [17].

It is necessary to take into account that simultaneously with the signal $\mathrm{I}_{\mathrm{C}}$, the traction current $\mathrm{I}_{\mathrm{T}}$ flows through the main threads, which, passing through the main winding of the $\mathrm{CT}$, forks and flows along each rail line in one direction. In this case, the traction current creates a magnetic field around each rail, covering the receiving coils of the locomotive and directing EMF in them $\left(\mathrm{e}_{\mathrm{tl}}-\right.$ in the left coil, $\mathrm{e}_{\mathrm{tr}}-$ in the right coil). The directions of these EMF are the same, since the directions of the traction currents that created them are the same. With respect to the traction current, the coils are inversely connected, therefore, $\mathrm{e}_{\mathrm{tl}}$ and $\mathrm{e}_{\mathrm{tr}}$ are mutually destroyed one other and not interfere with the reception of the signal current $I_{k}$. If there is a so-called longitudinal asymmetry of the traction current (the characteristics of the left rail thread do not coincide with the characteristics of the right one), the values of the $e_{t l}$ and $e_{t r}$ induced in the receiving coils are different and full compensation of these EMF does not occur, thus there is an interfering effect of the traction current on the ALSN devices which may cause the system to malfunction and endanger the safety of trains.

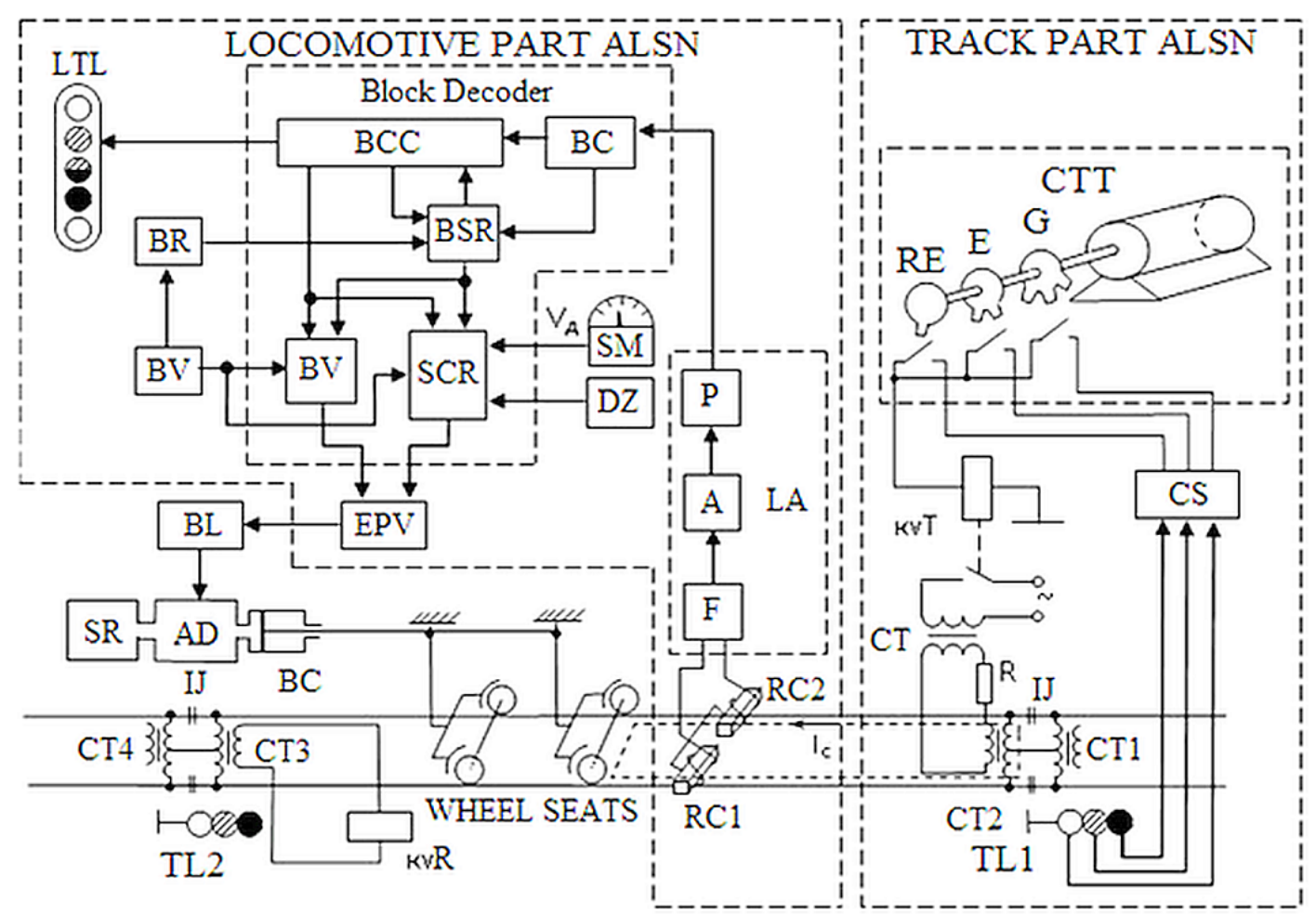

Fig. 2. Block diagram of ALSN

Listed in the RC EMF act consistently and generate the code current $I_{k}$ passing through the filter $(F)$ to the locomotive amplifier (LA). The pulsed relay (P) at the output of the amplifier is a repeater of the code, sending it to the decoder (BD) as an encrypted signal reading. The decoder contains a series of relays, which are combined into several blocks. Blocks of the counter (BC) - includes relay-counters, which provide the calculation of the number of pulses and intervals between them. Block signal relay $(B S R)$ - includes signal relay "G" (green 
light), "E" (yellow light), "RE" (red-yellow light), which create corresponding circuits of power supply of signal lamps of locomotive traffic light. Controlling Conformity Block (BCC) - ensures control over the compliance of the accepted code and status of the BSR signal relays by comparing them. The Conformity Block periodically after $5-6 \mathrm{~s}$ connects the signal relays to the relay-counters, in order for the locomotive traffic light to turnthe desired fire. Thus, the change in the lights of the locomotive traffic light occurs with a delay of $5-6$ seconds. This time corresponds to the reception of three series of code pulses. Speed control unit - contains a speed control relay (SCR) that interacts with a locomotive speedometer. Block of vigilance (BV) - carries out control of vigilance of the machinist. When changing the light of a locomotive traffic lights, for example from green to yellow, the electric circuit of the coil of the electropneumatic valve (EPV) ruptures and an acoustic signal sounds for 7 to 8 seconds. By the end of this time, the machinist must press the lever (button) of vigilance (BV) and thereby restore the supply circle of the EPV reel and stop the sound of the whistle [3].

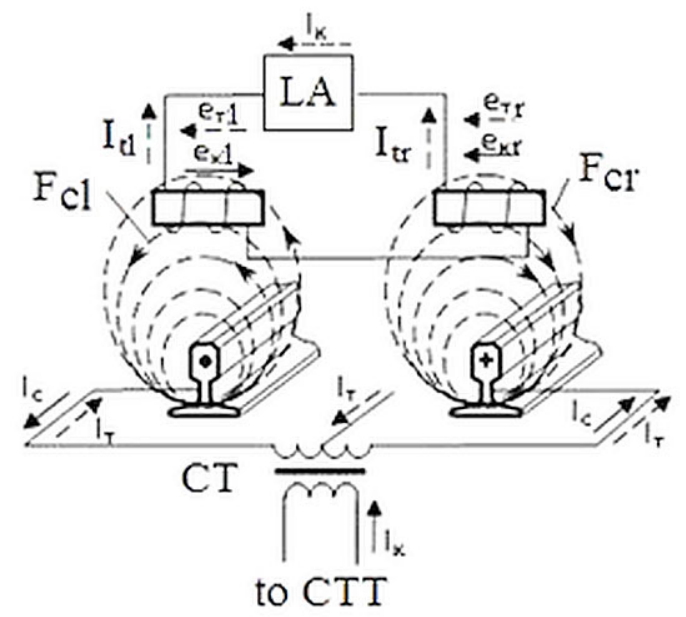

Fig. 3. Current direction in the rails and the receiver coils

If this does not happen, at the end of $7-8 \mathrm{~s}$ the EPV breaks and releases air from the brake line (BL), which leads to a redistribution of air pressure in the air distributor (AD) and the combination of spare reservoirs (SR) with brake cylinders (BC). In this situation, the train enters the emergency braking mode.

\section{Mathematical model}

To understand the processes taking place in the ALSN system and constructing a mathematical model of the communication channel between the input devices of the system in the form of an equivalent circuit for replacing the input filter and the track circle through which the signal current flows through the tools of the MATLAB software environment and the Simulink extension, let's construct a mathematical model $[19,20]$. To do this we use the most visual and easy to perceive the version of the representation of the filter scheme at a frequency of $50 \mathrm{~Hz}$ (fig. 4) [17].

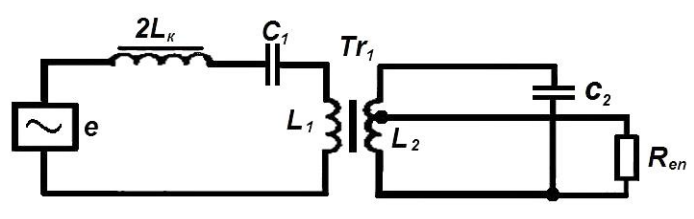

Fig. 4. Filter pattern $50 \mathrm{~Hz}$

The first circuit includes the inductance of the two receiving coils, as well as the inductance of the coupling $\mathrm{L}_{1}$ formed by the input circuit of the transformer $\operatorname{Tr}_{1}$ and the $\mathrm{C}_{1}$ capacitor. The Q-factor of this contour is 3-4. Also, this circuit includes a source e, which generates ALSN signals. The second contour is made by another winding of a transformer with inductance $\mathrm{L}_{2}$ and a capacitor $\mathrm{C}_{2}$ (these filter elements are located in the amplifier block). The quality of this contour is equal to 10 . From the part of the winding of the transformer $\operatorname{Tr}_{1}$, the received signal is fed into the first cascade of an amplifier with a load. Due to the inductive coupling and the setting of the contours in the resonance, they create a filter that passes with only a certain frequency band, which is a collection that has filtering properties. Such a filter is electrically equivalent to two consecutively connected circuits: a sequence of elements of the first circuit (receiving coils and capacitor $\mathrm{C}_{1}$ ) and a parallel circuit with an inductive resistance communication and a $\mathrm{C}_{2}$ capacitor. This system of contours has two frequencies of a successive and one of a parallel resonance.

The filter has a bandwidth of approximately $14 \mathrm{~Hz}$ and suppresses interference with a frequency below $10 \mathrm{~Hz}$ induced by the fluctuations of the receiving coils in the magnetic field of the traction current during the movement of the locomotive as well as by the influence of harmonics with a frequency of $100 \mathrm{~Hz}$ and above that appear under influence of contact network.

We created the mathematical model using the following blocks (fig. 5):

Scope - oscilloscope;

AC Voltage Source - Variable Voltage Source;

Ideal Switch - switch;

Current Measurement - ammeter;

$2 \mathrm{Lk}$ - inductance of two receiving coils;

C1, C2 - capacitors;

$\operatorname{Tr} 1$ - transformer;

Rvx - load of the amplifier.

Signal Builder - block for generating the following codes:

$\mathrm{G}$ - generator of the green light code $(\mathrm{G})$;

$\mathrm{E}$ - code generator for yellow light $(\mathrm{E})$;

$\mathrm{RE}$ - red-yellow code generator (RE).

The parameters of these generators, create combinations of intervals and pulses of a certain duration that accurately reflect the combinations of the corresponding code signals are shown on the oscilloscope (fig. 6). Electrically, according to the current technical conditions, the receiving coil is characterized by the following parameters: active resistance to alternating current with frequency $50 \mathrm{~Hz}$ more than $650 \mathrm{Ohms}$, inductance 7,1 $\pm 0,35 \mathrm{Gn}$, Q-factor 3,5. 


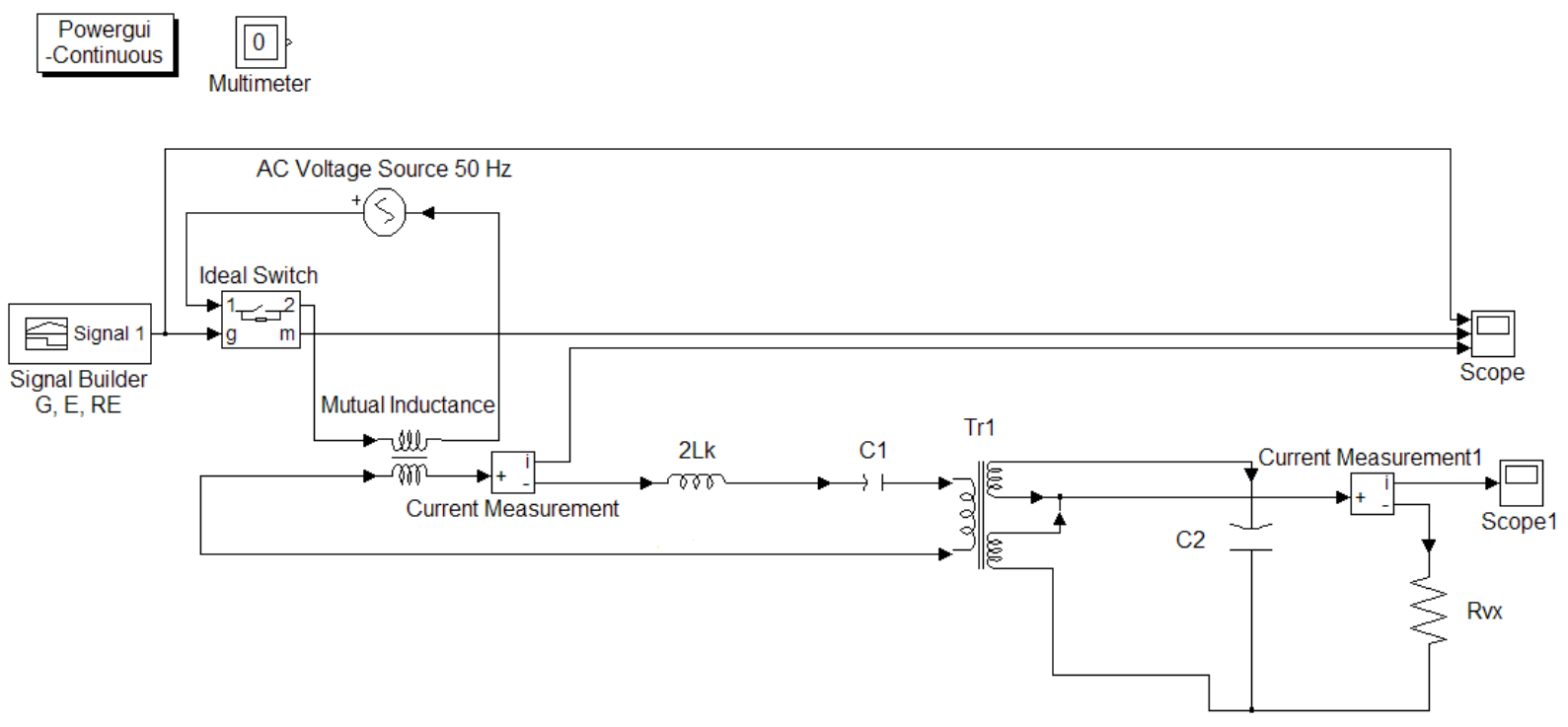

Fig. 5. Mathematical model of input devices ALSN

The filter transformer and its capacitors are included in the design of the amplifier itself (type УK25/50M). The primary winding I (820 turns) is included with the capacitors $\mathrm{C} 1$ (МБГП type, $0,75 \mu \mathrm{F} \pm 5 \%, 200 \mathrm{~V}$ ) in the outlet of the receiving coils. The secondary winding II (1700 turns with taps from 60, 75, 90 and 105 turns) has an additional sectional winding III (161 turns with taps from the 92nd and 115th turns), with the help of which the second contour with the $\mathrm{C} 2$ capacitors (capacity $4 \mu \mathrm{F}$ $\pm 5 \%, 200 \mathrm{~V}$ ) is tuned to resonance at a frequency of $50 \mathrm{~Hz}$. The magnet wire of the transformer has a fixed air gap of $0,9 \mathrm{~mm}$ to stabilize the inductance of its windings.

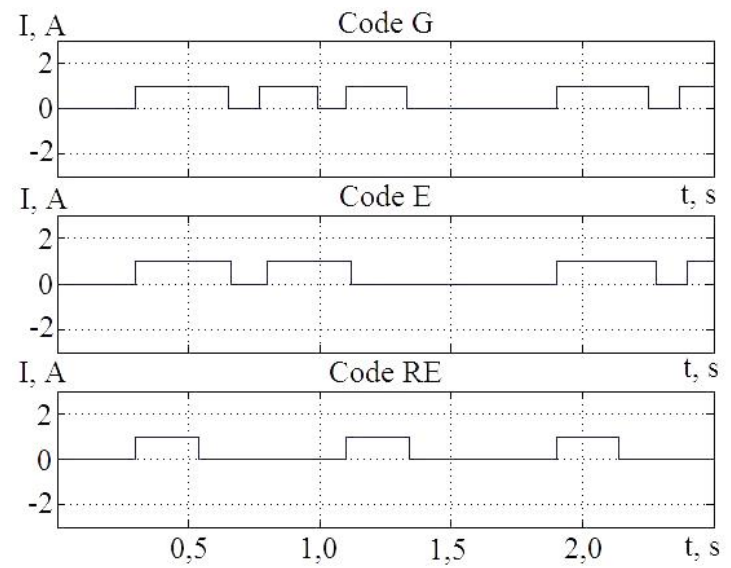

Fig. 6. Code signals G, E, RE

Unlike the specified parameters of the ALSN system, the mutual inductance between the rails and receiving coils must be calculated. In order to determine the value of the mutual inductance of the signal transmission channel to the locomotive, on first stage it is necessary to perform measurements of the voltage and current in the receiving coils using an ammeter [21]. The values obtained in normal conditions for the coil are $\mathrm{I}=0,00818 \mathrm{~A}$ and $\mathrm{U}=19,25 \mathrm{~V}$. Next, let's take a look a signal transmission channel which contains of a rail line, an ALSN receiving coil, and an ALSN code device. In order to make it possible, it is necessary to determine the active specific resistance of the rack thread to the alternating current by the formula (1)

$$
\mathrm{R}_{\mathrm{a}}=\frac{2,8 \cdot \sqrt{\mu \cdot \rho \cdot \varphi}}{\mathrm{u}}
$$

where $\mu=100-$ relative magnetic permeability of the track circle;

$\rho=0.21 \cdot 10^{-6} \mathrm{Ohm} \cdot \mathrm{m}-$ resistance of the metal of the track circle;

$\varphi=50 \mathrm{~Hz}-$ frequency of the current of the rail circle;

$u$ - the perimeter of the cross section of the rails.

Then, substituting the values of the parameters for the formula (1) we obtain the necessary value:

$$
\mathrm{R}_{\mathrm{a}}=\frac{2,8 \cdot \sqrt{100 \cdot 0.21 \cdot 10^{-6} \cdot 50}}{0,070}=1,296 \mathrm{Ohm} \text {. }
$$

The next step is to determine the internal specific inductance of the track circle by the formula:

$$
\mathrm{L}_{\mathrm{i}} \approx 0.0955 \cdot \frac{\mathrm{R}_{\mathrm{a}}}{\varphi}=0.0955 \cdot \frac{1,296}{50}=4.947 \cdot 10^{-4} \mathrm{Hn}
$$

Let's substitute the obtained values for the formula for determining the mutual inductance and calculate its value:

$$
\mathrm{M}=\frac{1}{2 \mathrm{\imath} \omega} \cdot\left[\frac{\mathrm{U}}{\mathrm{I}}-\mathrm{R}_{\mathrm{a}}-\mathrm{R}_{\mathrm{K}}\right]+\frac{1}{2} \mathrm{~L}_{\mathrm{i}}+\frac{1}{2} \mathrm{~L}_{\mathrm{\kappa}}
$$

where $\mathrm{L}_{\mathrm{\kappa}}=7,1 \Gamma_{\mathrm{H}}$ - inductance of the ALSN coil;

$\mathrm{R}_{\mathrm{K}}=110 \mathrm{Ohm}-$ resistance of the ALSN coil. 


$$
\begin{aligned}
& \mathrm{M}=\frac{1}{2 \cdot 0,7 \cdot 2 \cdot 3,14 \cdot 50} \cdot\left[\frac{19,25}{0,00818}-1,296-110\right]+ \\
& +\frac{1}{2} \cdot 4,947 \cdot 10^{-4}+\frac{1}{2} \cdot 7=5,11 \mathrm{Hn}
\end{aligned}
$$

\section{Results}

The time dependencies of the current change at the filter output when the system input codes G, E, and RE are obtained using Matlab (fig. 7, fig. 8, fig. 9) [22, 23].

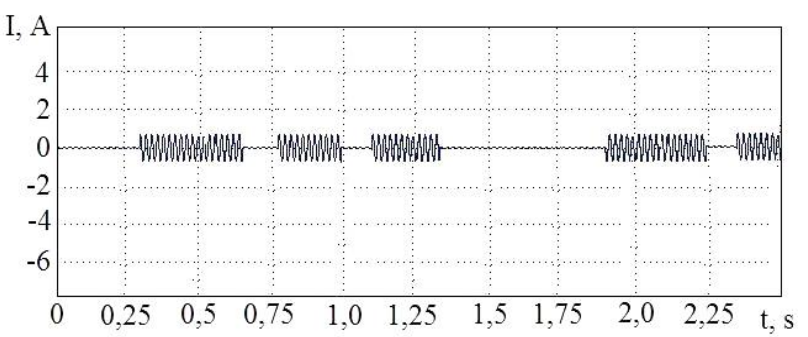

Fig. 7. Coded signal $\mathrm{G}$ at the filter output

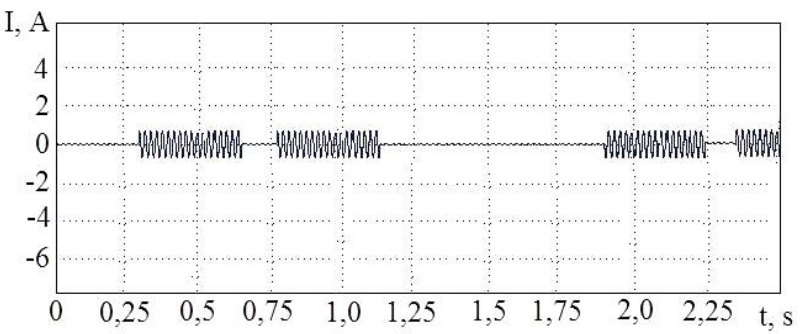

Fig. 8. Coded signal $\mathrm{E}$ at the filter output

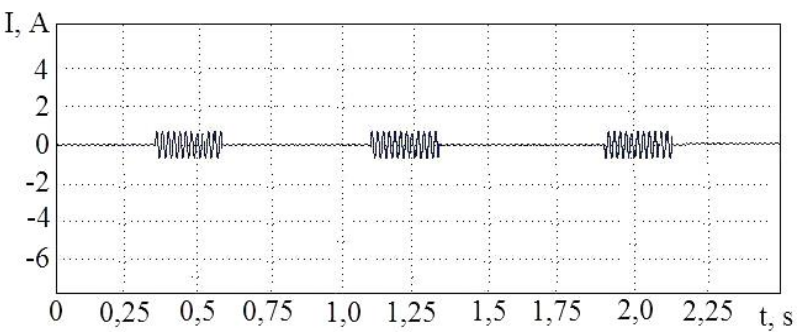

Fig. 9. Coded signal RE at the filter output

For comparison, we give an example of an image of ideal code signals measured by a laboratory car (Fig. 10, Fig. 11, Fig. 12).

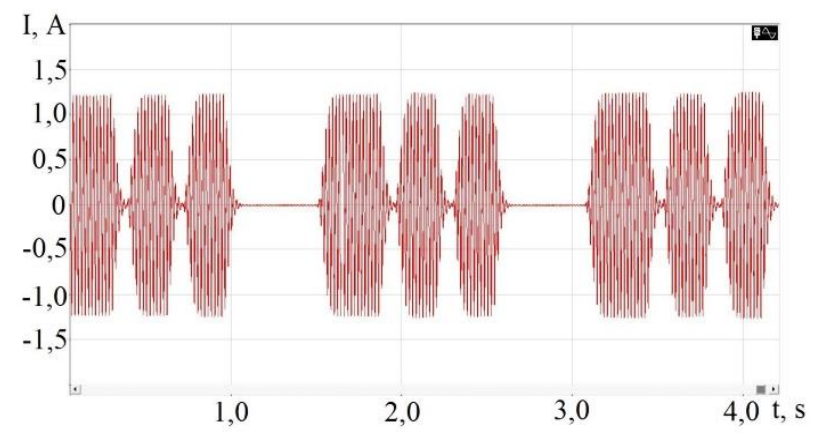

Fig.10. Coded signal G

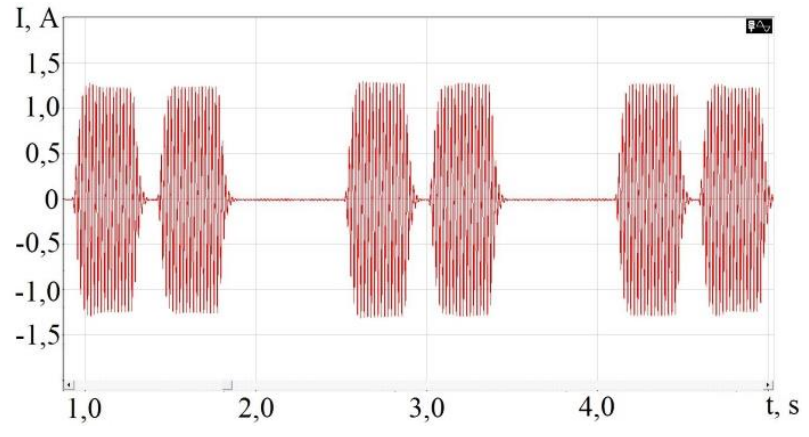

Fig. 11. Coded signal E

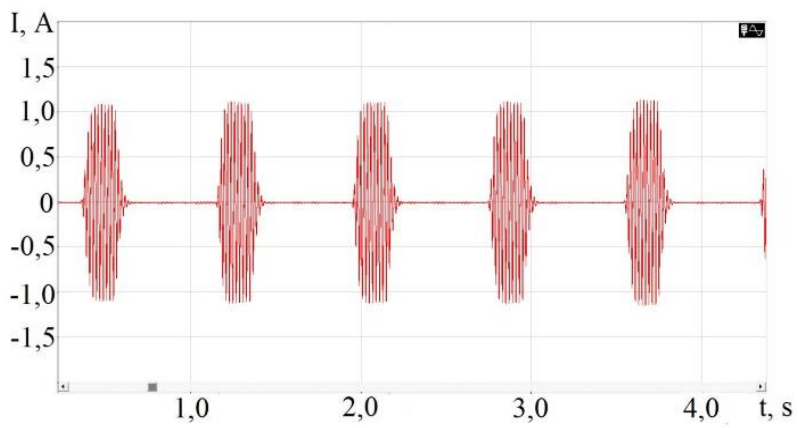

Fig. 12. Coded signal RE

From the results of the simulation, it can be seen that the developed model reproduces the ideal signal in realworld devices.

According to the work results of the mathematical model of the communication channel between the input devices of the system of automatic locomotive signalling of a continuous type with numerical coding in the form of an equivalent circuit for replacing a filter with a frequency of $50 \mathrm{~Hz}$ and a track circle, on which the signal current flows, it can be established that the signal at the output of the model satisfactorily coincides with real measurements, which testifies to the adequacy of the built system.

\section{Conclusions}

On the basis of the analysis of the structure and functioning of the devices of the ALSN system, a mathematical model of the communication channel of its input devices with the ALSN rail line was developed taking into account the mutual inductance between the rails and the locomotive receiving coils. The results of modeling at the filter output are presented at the input of all types of code combinations. Since the signals obtained from the model, and measured from the laboratory car, agree satisfactorily, then the developed model of input devices of the receiver ALSN corresponds to its real analog. This makes it possible to experimental study with the ALSN in the conditions of interference and distortion of the code signal, as well as research and determination of the behavior of the circuit during normal operation and in the event of interference without leaving the area of interference in the virtual environment of the mathematical package MATLAB and its extension Simulink. 
Thus, the ability to simulate the emergence of probable complex situations that lead to code crashes and the development of ways to detect, prevent and protect the action of devices from them was created. There is also the possibility in MATLAB and Simulink to develop and apply various circuitry solutions to reduce the impact of interference on the functionality of ALSN.

\section{References}

1. V. Gavrilyuk, T. Serdyuk, Telemetric system for the control of signal parameters of rail circuits. Transport systems telematics. II International Conference. Katowice-Ustron (Poland), 185-190 (2002)

2. V. Gavrilyuk, A. Zavgorodnyj, Computer simulation of electromagnetic interference from railway electric power system harmonics. Archives of transport system telematics, Vol. 2, № 1, 33-37 (2009)

3. Vl. V. Sapozhnikov, I. M. Kokurin, V. A. Kononov, A. A. Lykov, A. B. Nikitin Jekspluatacionnye osnovy avtomatiki $i$ telemehaniki: Uchebnik dlja vuzov zh.-d. transporta. M., Marshrut, 247 (2006) [in Russian]

4. T. E. Kijakina, Prichiny sboev $v$ rabote avtomaticheskoj lokomotivnoj signalizacii, metody reshenija problem Tehnicheskie nauki v Rossii i za rubezhom: materialy II mezhdunar. nauch. konf., 47-49 (2012) [in Russian]

5. V. L. Grigor'ev, A. V. Kotel'nikov, Optimizacija jelektroprovodnosti rel'sovogo styka pri propuske tjazhelovesnyh poezdov. ASI 8, 13-16 (2005) [in Russian]

6. V. I. Shamanov, Ju. A. Trofimov, Assimetrija tjagovyh tokov pod katushkami. ASI 11, 37-39 (2008) [in Russian]

7. S. V. Lukojanov, Sboev kodov ALSN na skorostnom uchastke stalo men'she. ASI 9, 22-25 (2011) [in Russian]

8. I. N. Sheverdin, V. I. Shamanov, Vlijanie tjazhelovesnyh poezdov na rel'sovye cepi i ALS, ASI 8, 24-29 (2004) [in Russian]

9. E. V. Gorenbejn, Sboi kodov ALSN $i$ ih uchet. ASI 7, 8-22 (2012) [in Russian]

10. V. B. Leushin, Analiz prichin sboev v sisteme ALSN. ASI 4, 20-25(2013) [in Russian]

11. S. V. Lukojanov, Sboev kodov ALSN na skorostnom uchastke stalo men'she. ASI 11, 34-36 (2011) [in Russian]
12. N. N. Baluev, Razvitie sredstv ZhAT. Strategija $i$ taktika. ASI 8, 2 (2012) [in Russian]

13. S. Ju. Burjak, V. I. Gavriljuk, O. A. Gololobova, Issledovanie vremennoj zavisimosti i spektral'nogo sostava signala $v$ cepi strelochnyh jelektrodvigatelej peremennogo toka. Nauka i progress transporta. Vestnik DNUZhT. D., DNUZhT, 54, 7-22 (2014) [in Russian]

14. S. Ju. Burjak, V. I. Gavriljuk, O. A. Gololobova, M. A. Kovrygin, Distancionnoe diagnostirovanie sostojanija strelochnyh perevodov po vremennoj harakteristike $i$ spektral'nomu sostavu tokovoj krivoj. Nauka ta progres transportu. Vestnik DNUZhT. D., DNUZhT, 56, 7-24 (2015) [in Russian]

15. A. M. Safarbakov, A. V. Luk'janov, S. V. Pahomov, Osnovy tehnicheskoj diagnostiki detalej $i$ oborudovanija: uchebnoe posobie. Irkutsk, IrGUPS, 128 (2007) [in Russian]

16. S. V. Shvecov, A. S. Talyzin, N. V. Esin Metodicheskie ukazanija $k$ vypolneniju laboratornyh rabot pri izuchenii discipliny «Bezopasnost" vozhdenija poezdov» Omsk, 48 (2010) [in Russian]

17. N. F. Kotljarenko, A. V. Shishljakov, Ju. V. Sobolev, I. 3. Skripin, N. A. Shishljakin, Putevaja blokirovka i avtoregulirovka: uchebnik dlja vuzov. M., Transport, 408 (1983) [in Russian]

18. G. Theeg, S Vlasenko, Railway Signalling and Interlocking. International Compendium. Hamburg, Eurail-press Publ., 448 (2009)

19. O. Beucher, Introduction to MATLAB \& Simulink: a project approach. Hingham, Massachusetts New Delhi, Infinity Science Press LLC, 390 (2008)

20. I. V. Chernyh, Modelirovanie jelektro-tehnicheskih ustrojstv v MATLAB SimPowerSystems i Simulink, M., DMK Press, 288 (2008) [in Russian]

21. L. A. Bessonov, Teoreticheskie osnovy jelektrotehniki. M., Vysshaja shkola, 515 (1996) [in Russian]

22. L. F. Chaparro, Signals and Systems Using MATLAB Dep. of Electrical and Computer Eng. Univ. of Pittsburgh. Amsterdam, Boston, Heidelberg, London, New York, Oxford, Paris, San Diego, San Francisco, Singapore, Sidney, Tokyo: Academic Press, 752 (2011)

23. R. J. Tervo Practical Signals Theory with MATLAB Applications, Hoboken, New Jersey, Wiley, 486 (2014) 